\title{
Inclusão política? Recrutamento e seleção de atores nas conferências de políticas públicas ${ }^{1}$
}

$\begin{array}{r}\text { Cláudia Feres Faria } \\ \text { Isabella Lourenço Lins } \\ \hline\end{array}$

\section{Introdução}

As conferências de políticas públicas no Brasil (doravante CPPs) tornaram-se espaços privilegiados de definição compartilhada da agenda de uma determinada política pública desde que o Partido dos Trabalhadores (PT) assumiu a presidência do Brasil em 2003. A partir desse ano, tanto o número quanto os tipos de conferências cresceram: 138 conferências foram realizadas em diferentes áreas de políticas públicas, segundo levantamento até 2016 (Souza et al., 2013)².

Em tese, com o aumento do número e dos tipos de conferências, crescem as chances de ampliação da participação dos cidadãos nessas inovações, uma vez que todos os afetados pela temática têm o direito de participar. Entretanto, na prática, a participação nas inovações democráticas sofre uma série de constrangimentos que inibem a inclusão de novas vozes aos processos discursivos e decisórios por elas promovidos (Verba, Schlozman e Brady, 1995; Fung, 2006; Smith, 2009; Ryfe e Stalburg, 2012).

Diante de tal constatação, este artigo busca avaliar a capacidade inclusiva das CPPs por meio de uma estratégia analítica que envolve três passos distintos. Através de um survey realizado com 729 participantes das Conferências de Saúde (CS) e de Assistência Social (CAS) de 2011 em Minas Gerais ${ }^{3}$, as autoras analisam comparativamente (1) quem são os(as) participantes dessas conferências, (2) o impacto da mudança de escala no perfil socioeconômico e político desses participantes e (3) as regras referentes ao recrutamento

\footnotetext{
1 Este artigo se apoia em dados oriundos de diferentes projetos de pesquisa financiados pela Fapemig (APQ02772-14) e pelo CNPq (305022/2015-6). As autoras agradecem às agências de fomento pelo apoio financeiro recebido. Agradecemos ainda ao Leandro Alves (Cedeplar-UFMG) pelo manuseio dos dados, aos organizadores do GT 10 - Democracia e Desigualdades da Anpocs pelos comentários à primeira versão do artigo que se encontra em <http://www.anpocs.com/index.php/papers-39-encontro/gt/gt10>. Por fim, gostaríamos de agradecer também os dois pareceristas anônimos, cujas críticas e sugestões contribuíram para a versão final do artigo. A responsabilidade pelo produto final é, entretanto, toda das autoras.

2 De acordo com Souza et al. (2013), as conferências podem ser classificadas de acordo com a afinidade temática das áreas de políticas públicas com as quais elas estão vinculadas: (1) Saúde, (2) Estado, Economia e Desenvolvimento, (3) Meio ambiente, (4) Educação, Cultura e Assistência Social, (5) Direitos Humanos e (6) Minorias.

${ }^{3}$ A Tabela 1 mostra o número de respondentes por escala nas duas políticas: os 337 respondentes das CS estão assim divididos: 111 oriundos da etapa distrital, 154 da municipal, 59 são delegados estaduais e 13 da etapa nacional. Dos 392 respondentes da CAS, 123 são oriundos da etapa distrital, 117 da municipal, 55 são delegados estaduais e 7 são oriundos da etapa nacional.
} 
(quem pode participar) e ao processo representativo nessas inovações (como os(as) delegados(as)-representantes são selecionados(as)).

Entendendo inclusão política como a presença de diferentes atores e atrizes no processo de participação, representação e deliberação ensejado pelas CPPs, a análise proposta se justifica uma vez que parte delas ocorre em todo o território nacional, começando no nível local e seguindo até o nível nacional. O processo de nacionalização da participação social por meio dessas conferências é realizado através de uma engenharia institucional que envolve um conjunto de regras relativas a quem pode participar e representar. Nos níveis locais, é permitida a presença, com direito a voz e voto, de todos os cidadãos afetados pela temática em debate e, nos demais níveis, instaura-se a representação de delegados(as) selecionados(as) nas etapas anteriores.

Sabe-se que uma cidadania inclusiva, para se concretizar, requer atenção tanto às distorções comumente derivadas da participação - os mais interessados em participar e/ou os que já participam (Verba, Schlozman e Brady, 1995; Fung, 2006; Dahl, 2006) - quanto da representação - seleção de apenas algumas vozes em detrimento de outras em função do desempenho cognitivo (Schumpeter, 1961; Downs, 1999) e/ou da trajetória participativa (Verba, Schlozman e Brady, 1995).

Por meio da análise de quem participa, objetiva-se, portanto, avaliar a presença ou não de uma pluralidade de participantes nas conferências analisadas. Para tal, o estudo é realizado com base nos perfis socioeconômicos e políticos desses participantes, a partir das variáveis de renda, sexo, escolaridade e vínculos participativos. Analisamos ainda o impacto da mudança de escala - distrital, municipal, estadual e nacional - nesses perfis com o objetivo de aferir em que medida o processo representativo gestado no interior do ciclo de conferências é capaz de manter e/ou promover a pluralidade aludida.

Por fim, o exame das regras pretende avaliar em que medida elas afetam a extensão na qual a inclusão é realizada. Assim, além de investigar o perfil de quem participa e de quem é selecionado como representante para as escalas superiores, é necessário avaliar se e em que medida o desenho institucional das conferências favorece um padrão normativo que coíba os constrangimentos derivados tanto da participação quanto da representação, garantindo assim a inclusão necessária para a democratização dessas inovações.

Esse diagnóstico é realizado com base na análise dos Regimentos Internos (RI) de cada conferência, que considera ainda as suas possíveis mudanças relativas ao recrutamento e à seleção ${ }^{4}$. Assim sendo, o estudo proposto é simultaneamente descritivo e normativo: descreve, com base em dados primários, os perfis dos(as) participantes,

\footnotetext{
${ }^{4}$ O Regimento Interno é um documento da Conferência que contém as regras que ordenam a sua dinâmica. Ele é usualmente elaborado pelos representantes da sociedade civil e do governo nas Comissões Organizadoras das respectivas conferências e é reelaborado pelos participantes nas Plenárias Iniciais (para análise dessa dinâmica ver Faria e Lins, 2013).
} 
assim como avalia as potencialidades de ampliação da inclusão política nessas inovações por meio de dados referentes às regras das CPPs e suas possíveis mudanças.

Para realizar os objetivos propostos, este artigo está dividido nas seguintes seções: breve revisão da literatura acerca das condições e critérios que determinam o caráter democrático das inovações democráticas na seção "O que é democrático nos arranjos participativos?"; apresentação do objeto de análise e da metodologia utilizada em "Das conferências, dos dados e da metodologia de análise"; na terceira seção "Descrição e análise comparada dos perfis socioeconômico e político dos(as) participantes das Conferências de Saúde (CS) e Conferências de Assistência Social (CAS)" e suas subseções, apresentamos a análise dos perfis socioeconômico e político dos(as) participantes com base em atributos pessoais e a análise da relação entre os perfis encontrados e o desenho institucional das duas conferências; e a explicação das diferenças na capacidade inclusiva das CPPs com base na relação entre perfil socioeconômico e político dos(as) participantes, escala e desenho institucional encontra-se na seção "Escala e inclusão política nas conferências de saúde e assistência social".

\section{O que é democrático nos arranjos participativos?}

Em suas reflexões sobre a possibilidade e a desejabilidade da democracia, Dahl $(2000,2006)$ recomenda um conjunto de critérios que funciona simultaneamente como crítica às democracias existentes e horizonte a ser perseguido. Segundo o autor, uma democracia ideal requer no mínimo: (1) participação efetiva, que pressupõe oportunidade igual e real para todos os membros de uma comunidade vocalizarem suas visões sobre o conteúdo da política; (2) pesos iguais na escolha das alternativas, o que pressupõe oportunidade igual e efetiva para todos os membros da comunidade votarem nas alternativas; (3) entendimento esclarecido, que pressupõe oportunidade igual e efetiva para todos os membros de uma comunidade aprenderem sobre as alternativas em jogo e suas consequências; (4) controle da agenda, que pressupõe chances iguais e efetivas de definir os temas e as políticas que serão colocados na agenda; e (5) inclusão de todos os adultos no processo democrático (Dahl, 2006).

Cada um desses critérios está vinculado a um conjunto já conhecido de constrangimentos impostos às possibilidades de democratização das democracias modernas. Taxas diferenciadas de condições e motivações para participar geralmente limitam as possibilidades de participação e a igualdade de escolha das alternativas. A literatura sobre o tema afirma que aqueles que usualmente participam são cidadãos que apresentam maior nível de renda e de educação, maior interesse e engajamento nas questões políticas (Verba, Schlozman e Brady, 1995).

Encontramos sempre uma associação positiva entre recursos socioeconômicos, políticos e poder decisório. Verba, Schlozman e Brady (1995) mostram que indivíduos com maior acúmulo de recursos - econômicos, organizacionais e informacionais - são os mais 
"ouvidos". Vocalizam com mais eficiência suas preferências e, consequentemente, impactam mais os governos. Por isso, as assimetrias organizacionais, informacionais e/ou econômicas impõem constrangimentos à participação dos atores societários e afetam o seu grau de influência nos processos de decisão pública e no sistema político como um todo.

Young (2002) reforça igualmente o problema das desigualdades de voz. Segundo essa autora, para além da presença nos arranjos participativos - relativa à igualdade externa - é preciso lidar com os problemas oriundos da desigualdade de voz e, consequentemente, da influência nas decisões no interior desses mesmos espaços - a igualdade interna.

O critério "entendimento esclarecido", enfatizado por Dahl (2006), está diretamente ligado a esse segundo aspecto da desigualdade. A compreensão sobre os processos, o conteúdo e as consequências das políticas impactam simultaneamente a capacidade de influência dos atores nas decisões políticas e o controle dessas decisões. Tais ganhos de entendimento são, entretanto, dificultados pela motivação, habilidade e/ou competência para participar, criando assim um círculo vicioso.

Além das limitações apontadas, tem-se o problema da escala. A mudança de escala é quase sempre acompanhada por maior complexidade, que, por sua vez, requer mais expertise para resolvê-la. A divisão de trabalho requerida demanda, muitas vezes, maior capacidade de coordenação dos cidadãos para intervirem e controlarem os resultados políticos finais (Dahl, 2000).

Para contornar os constrangimentos aludidos, uma das alternativas sugeridas vincula-se à reflexão e à mudança em relação aos desenhos institucionais das inovações que têm como objetivo a inclusão política dos cidadãos dessas sociedades. Uma vez que os desenhos retratam as interações sociais e políticas que os conformam, eles podem ser alterados mediante um processo que envolve "reflexividade institucional", ou seja, a oportunidade e a capacidade de os atores envolvidos nessas inovações debaterem, reinterpretarem e mudarem coletivamente suas regras (Bohman, 1996; Landwehr, 2015).

Quais regras seriam passíveis de reflexão e mudança nos casos analisados?

A literatura especializada sugere que formas diferentes de recrutamento impactarão diferentemente quem pode participar (Smith, 2009; Fung, 2006; Verba, Schlozman e Brady, 1995). Inovações democráticas abertas à participação de todos, como as CPPs analisadas, demandam atenção para o perigo da sobrerrepresentação de alguns grupos sociais em detrimento de outros, com menos recursos materiais e simbólicos. É preciso analisar, portanto, se as regras que promovem a presença de grupos historicamente sem acesso a essas arenas estão sendo debatidas e revistas e se existem incentivos para mobilizar e oferecer apoio e recursos àqueles cidadãos com pouca experiência e confiança para que eles participem e se expressem publicamente (Smith, 2009).

Os problemas derivados da escala e, consequentemente, da representação podem encontrar nesse processo de reflexão institucional outra resposta, uma vez que critérios 
tradicionais, como a proporcionalidade baseada no tamanho do território e da população, podem ser conjugados àqueles vinculados à presença de grupos marginalizados e à promoção de suas capacidades de expressão e vocalização (Phillips, 1995; Young, 2002). Tais mudanças podem promover simultaneamente a pluralidade na participação e na representação (Lüchmann, 2007; Lavalle e Castello, 2008; Abers e Keck, 2009; Almeida, 2013).

A possibilidade de reinterpretar coletivamente as normas dos arranjos participativos - "reparando-as reflexivamente" (Bohman, 1996) - passa a constituir, portanto, parte fundamental do processo e das mudanças almejadas em um contexto marcado por assimetrias de recursos econômicos, organizacionais e informacionais, incidindo diretamente sobre o caráter inclusivo desses arranjos.

No caso das CPPs, a discussão e a mudança coletiva do Regimento Interno (RI) constituem um momento importante das suas dinâmicas. Através dele, abre-se a possibilidade de (re)definição das regras que permitem rever a abrangência inclusiva desses arranjos. Assim sendo, a análise do perfil socioeconômico e político de quem entra e de quem é selecionado como representante (terceira seção), bem como a das regras que ordenam essas dinâmicas (quarta seção), justifica-se, uma vez que apontam o quão reflexiva e inclusiva essas inovações são e/ou podem vir a ser.

\section{Das conferências, dos dados e da metodologia de análise}

\section{Caracterização e dinâmica das CPPS}

As CPPs constituem mais uma inovação democrática no Brasil, as quais (1) promovem a participação voluntária de atores da sociedade civil, do Estado e do setor privado e (2) se organizam em todo o território nacional em um conjunto de assembleias que nacionalizam a participação. Por isso, elas são aqui definidas como arranjos institucionais de participação, representação e deliberação que requerem esforços diferenciados de mobilização social, construção da representação política e diálogo em torno de seus propósitos (Faria, Petinelli e Lins, 2011).

Embora apresentem diferenças em suas dinâmicas, funções e desenhos institucionais ${ }^{5}$, boa parte delas possui etapas preparatórias - locais, distritais, municipais, estaduais e/ou regionais - que conferem a elas a ideia de "processo" ou "sistema" que

\footnotetext{
5 Tais diferenças levaram alguns autores a desenvolver uma tipologia das conferências. As conferências "típicas", majoritárias, apresentam parte das características aqui destacadas, enquanto as conferências "atípicas", minoritárias, se diferenciam por não apresentarem etapas municipais e intermunicipais e/ou plenárias e/ou por realizarem oficinas e grupos de trabalho. Elas apresentam ainda um potencial de mobilização menor, objetivos mais restritos e menos propositivos, voltados para a discussão de ideias e o agendamento de temas (Souza et al., 2013). Entretanto, mesmo nas CPPs "típicas" encontramos diferenças importantes como, por exemplo, a presença de plenárias temáticas e a eleição dos(as) representantes da sociedade civil para os conselhos na área de assistência social, mas não nas demais áreas.
} 
envolve todo o território nacional. Na base local, a participação é aberta à população e, nas demais etapas territoriais, o processo representativo ocorre mediante eleição e/ou indicação de delegados(as) (Souza et al., 2013; Teixeira, Souza e Lima, 2012; Pogrebinschi e Santos, 2011).

De um modo geral, as CPPs são convocadas pelo Poder Executivo e têm como atribuição a definição de propostas e/ou orientações que constituirão os Planos de Políticas Públicas para cada área envolvida. Quando propositivos, os planos podem orientar as ações de ambos os poderes, Executivo e Legislativo, em cada ente da federação. Além dessa atribuição, as CPPs podem cumprir a função de promoção da participação, de agenda e/ou de avaliação da implementação das políticas públicas (Souza et al., 2013).

No que diz respeito a sua organização, muitas delas apresentam ainda fases internas que compreendem o credenciamento, a sessão plenária de abertura, os grupos de trabalho, a sessão plenária final e a eleição de delegados(as), como são os casos das CPPs aqui analisadas.

Quadro 1

Dinâmica das CPPs analisadas

\begin{tabular}{|l|l|l|l|l|}
\hline & & Fase 3 & Fase 4 & Fase 5 \\
Fase 1 & Fase 2 & $\begin{array}{l}\text { Realização das } \\
\text { conferências } \\
\text { locais e } \\
\text { municipais }\end{array}$ & $\begin{array}{l}\text { Realização da } \\
\text { conferência } \\
\text { estadual }\end{array}$ & $\begin{array}{l}\text { Realização da } \\
\text { conferência } \\
\text { nacional }\end{array}$ \\
\cline { 2 - 5 } $\begin{array}{l}\text { Convocação das } \\
\text { conferências pelos } \\
\text { governos nacional e } \\
\text { subnacionais }\end{array}$ & $\begin{array}{l}\text { Posse dos Comitês } \\
\text { Organizadores nos } \\
\text { níveis nacional e } \\
\text { subnacionais }\end{array}$ & $\begin{array}{l}\text { Fases internas } \\
\text { Inscrição } \\
\text { Plenária de abertura } \\
\text { Grupo de trabalho } \\
\text { Plenária final } \\
\text { Eleição de delegados(as) }\end{array}$ \\
\hline
\end{tabular}

Fonte: Ramos e Faria (2013).

\section{Dados e metodologia}

Este artigo analisa dados referentes aos perfis socioeconômico e político dos(as) participantes das Conferências de Saúde (CS) e de Assistência Social (CAS), assim como o desenho institucional de cada uma delas.

Para obter os dados relativos aos perfis mencionados, montamos um banco de dados baseado nas listas de presença das conferências analisadas. Esses bancos contêm as seguintes informações: nome, contato telefônico e endereço dos participantes. A coleta desses dados foi comprometida em função (1) da recusa na liberação de algumas listas e 
da inexistência de outras e (2) da qualidade dos registros, como, por exemplo, ausência de telefones de contato e/ou endereços dos(as) participantes. Assim, somente os registros com telefone e endereços compuseram o banco de dados que contou com 2.447 participantes: 1.291 das Conferências de Saúde e 1.156 das Conferências de Assistência Social.

Restrições orçamentárias nos levaram a definir uma amostra de 1.200 participantes, distribuídos igualmente entre as duas conferências para minimizar os erros na comparação. A partir disto, foram estabelecidas as amostras por escala das conferências.

Para as escalas distrital e municipal, em Belo Horizonte, utilizou-se a amostra aleatória simples em ambas as conferências. Para a escala estadual, foram sorteados aleatoriamente os(as) delegados(as) eleitos(as) para a etapa nacional no caso da CS e, no caso da CAS, utilizou-se amostragem estratificada por mesorregiões ${ }^{6}$. Para a escala nacional, consideramos todos(as) os(as) delegados(as) de Belo Horizonte eleitos na etapa estadual.

Os participantes foram contatados por meio de ligações via Skype e responderam a um questionário eletrônico elaborado no Survey Monkey ${ }^{7}$. Problemas decorrentes de números errados de telefone, números inexistentes ou de trabalho, além das recusas durante a aplicação dos questionários, nos obrigaram a repensar a amostra, que passou de uma amostra inicialmente probabilística para uma amostra não probabilística, do tipo "por conveniência"8.

Nesse caso, a amostra foi composta por todos os participantes do banco contatados e que aceitaram ser entrevistados. Dessa forma, desconhecem-se as probabilidades com que foram selecionados para a entrevista. Ainda assim, os resultados alcançados revelam, no mínimo, um esboço inédito e instrutivo do universo de participantes dessas conferências.

A amostra por conveniência foi composta por 729 entrevistas: 337 entrevistas na Conferência de Saúde e 392 na Conferência de Assistência Social. No nível estadual, como o Conselho Estadual de Saúde de MG só disponibilizou os dados referentes aos(às) delegados(as) eleitos(as) para a etapa nacional, as entrevistas foram realizadas somente com os delegados do estado (L4). Para efeitos comparativos, na etapa estadual da Conferência de Assistência Social, foram realizadas entrevistas tanto com os participantes

\footnotetext{
${ }^{6}$ Como o Conselho Estadual de Saúde não disponibilizou a listagem de delegados(as) por mesorregião, não foi possível realizar o mesmo procedimento amostral. As mesorregiões são Campo das Vertentes, Central Mineira, Jequitinhonha, Metropolitana de BH, Noroeste, Norte de Minas, Oeste de Minas, Sul/Sudoeste de Minas, Triângulo/Alto Paranaíba, Vale do Mucuri, Vale do Rio Doce e Zona da Mata.

7 Todos os números telefônicos listados no banco de dados foram contatados. Quando necessário, pelo menos três tentativas foram feitas em dias e horários diferentes.

${ }^{8} \mathrm{Em}$ vários casos, os números de telefone registrados já não pertenciam às pessoas listadas ou não existiam mais. Muitos deles, principalmente das etapas distrital e municipal, eram de órgãos públicos. Por isso, diversos participantes listados não foram encontrados.
} 
da etapa estadual (L3) quanto com os(as) delegados(as) eleitos(as) para a etapa nacional (L4). O número de entrevistados em cada escala, para cada política, variou conforme reportado na Tabela 1:

Tabela 1

Entrevistas por escala e por conferência

\begin{tabular}{|c|c|c|c|c|c|c|}
\hline \multirow{2}{*}{ Escala } & \multicolumn{3}{|c|}{ Conferências de Saúde } & \multicolumn{2}{c|}{ Conferências de Assistência Social } \\
\cline { 2 - 7 } & $\begin{array}{c}\text { Total de } \\
\text { participantes }\end{array}$ & $\begin{array}{c}\text { No de } \\
\text { respondentes }\end{array}$ & $\mathbf{( \% )}$ & $\begin{array}{c}\text { Total de } \\
\text { participantes }\end{array}$ & $\begin{array}{c}\text { No de } \\
\text { respondentes }\end{array}$ & $\mathbf{( \% )}$ \\
\hline Distrital (L1) & 525 & 111 & 21,1 & 475 & 123 & 25,9 \\
\hline Municipal (L2) & 548 & 154 & 28,1 & 247 & 117 & 47,4 \\
\hline Estadual (L3) & - & - & - & 341 & 90 & 26,4 \\
\hline $\begin{array}{c}\text { Delegados(as) } \\
\text { do estado } \\
\text { (L4) }\end{array}$ & 201 & 59 & 29,4 & 80 & 55 & 68,7 \\
\hline $\begin{array}{c}\text { Delegados(as) } \\
\text { nacionais (L5) }\end{array}$ & 17 & 13 & 76,4 & 13 & 7 & 53,9 \\
\hline Total & $\mathbf{1 . 2 9 1}$ & $\mathbf{3 3 7}$ & $\mathbf{2 6 , 1}$ & $\mathbf{1 . 1 5 6}$ & $\mathbf{3 9 2}$ & $\mathbf{3 3 , 9}$ \\
\hline
\end{tabular}

Fonte: Faria (2015).

Variáveis

A distribuição de recursos e o nível de engajamento são determinantes importantes da participação política dos cidadãos estadunidenses na análise clássica realizada por

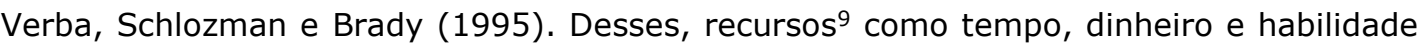
cívica são considerados preditores mais relevantes que os demais, mesmo que a capacidade explicativa dos mesmos varie conforme a atividade política analisada (Verba, Schlozman e Brady, 1995, p. 270).

Além das variáveis socioeconômicas, das habilidades organizacionais e de comunicação, a capacidade de mobilização das organizações e instituições também importa no modelo analítico elaborado por esses autores. Sua maior capacidade explicativa, quando comparado aos outros modelos baseados nas variáveis socioeconômicas ou no autointeresse dos atores, reside, segundo eles, exatamente na ampliação e combinação desses fatores que explicam a participação (Verba, Schlozman e Brady, 1995, p. 283)

A intenção aqui não é replicar, para os casos analisados, o modelo oferecido. Nossa metodologia de análise não nos permite seguir tal direção. O que fazemos é aferir, inspiradas nas variáveis explicativas ressaltadas pelo modelo do "voluntarismo cívico", a

${ }^{9}$ Recursos como tempo, dinheiro e habilidades cívicas são variáveis explicativas centrais do comportamento político também para a Teoria da Mobilização de Recursos (McCarthy e Zald, 1977), cuja unidade de análise são, entretanto, atores coletivos e não indivíduos. 
posição social e os vínculos associativos de quem chega nas conferências, a forma como são recrutados para as mesmas e o impacto da mudança de escala nesses perfis.

Em relação às variáveis socioeconômicas, além de renda e grau de escolaridade, o artigo avalia gênero, raça e faixa etária para uma melhor caracterização desses participantes. No que diz respeito às habilidades cívicas e ao nível de engajamento dos participantes, foram mobilizadas variáveis como fontes de informações sobre política, número de participação em atividades políticas ${ }^{10}$, anos de participação em conferências, número de conferências que já participou e interesse por política. Em relação ao recrutamento dos participantes, analisamos fontes de informação sobre as conferências e o desenho institucional.

Dado que a análise do desenho institucional se tornou central nas discussões sobre inovações democráticas pelo impacto que causam na quantidade e nos vieses da participação, no fomento das habilidades cívicas, no controle das decisões, entre outros elementos (Fung, 2004), analisaremos aqui as regras relativas aos processos de recrutamento e de seleção dos participantes por serem recorrentemente associadas à promoção desses vieses. Buscaremos analisar, simultaneamente, a presença ou não de debate e mudanças nas mesmas.

\section{Análise de correspondências múltiplas e análise estatística descritiva}

Os dados foram analisados por meio da análise de correspondência múltipla (doravante ACM) (Greenacre e Blaisus, 2006; Greenacre, 2007) e da Análise Descritiva.

A análise de correspondência múltipla é um método que explora a associação entre variáveis categóricas, quando há muitas variáveis e/ou categorias. A ideia chave é a associação que às vezes é tratada como correlação.

A vantagem do método é que ele explora associações que seriam difíceis de identificar. As associações podem ser vistas a partir da posição assumida pela nuvem de pontos, ou seja, pela distância/proximidade entre os pontos. Os pontos representam os atributos que as variáveis apresentam, mas não as próprias variáveis.

Os métodos de análise de correspondência são também úteis por sua apresentação visual. A leitura da distribuição dos pontos é um dos aspectos mais importantes. Quanto mais próximos os pontos, mais as categorias estão associadas e, quanto mais distantes, menos associadas estão as categorias. A questão é sempre sobre a proximidade (ou distância), mesmo quando analisamos diferentes quadrantes. Se as categorias estão no mesmo quadrante, espera-se haver maior proximidade. Mas algumas categorias podem estar associadas, mesmo estando em diferentes quadrantes. Sendo assim, é também

10 As atividades políticas sugeridas para as/os respondentes foram: conselhos gestores e de políticas; movimentos sociais; Ongs.; manifestações, coletas de assinaturas e abaixo-assinados; associações religiosas; associação de bairro; associações profissionais; orçamento participativo; campanhas políticas; partidos políticos e sindicatos. 
importante analisar como os pontos são distribuídos ao longo de cada dimensão. As dimensões representam um resumo das distâncias entre pontos.

A primeira dimensão sempre explica estatisticamente a maior parte da variância entre as categorias (inércia). A segunda dimensão explica menos, e assim por diante. Dado que o método é fortemente visual, é difícil analisar muitas dimensões. Além disso, há um limite para o número de dimensões, de modo que eles não podem alcançar $100 \%$ da variância explicada.

A variação é a diversidade dos atributos dos indivíduos. Assim, quanto maior for a variância (inércia) explicada pela soma das dimensões, mais o método refletirá o número de atributos do indivíduo.

As dimensões podem ser lidas através da distribuição dos pontos entre elas. Neste artigo, por exemplo, as categorias principais, as escalas das conferências, estão localizadas ao longo da dimensão 1 . Essa dimensão mostra que os atributos sociais e políticos dos participantes estão distribuídos de acordo com as escalas e explica a maior parte da variância. Ou seja, dependendo da escala, os participantes apresentarão um conjunto específico de atributos. Isso significa que os atributos são mais fortes em uma escala do que na outra, sem, contudo, significar que as outras escalas não apresentarão indivíduos com os mesmos atributos.

O que determina o conjunto específico de características que descrevem uma determinada escala será a proximidade entre esta e as categorias que a rodeiam. Pode ser que para uma escala as categorias estejam mais próximas e, para outra, não. Como uma análise exploratória, esse tipo de método é mais conveniente para este artigo.

Como a análise de correspondência múltipla evidencia as categorias mais salientes, as variáveis como gênero, faixa etária e fontes de informação sobre conferências não estão nos gráficos de pontos (Gráficos 1 e 2) e foram analisadas por meio da estatística descritiva.

\section{Descrição e análise comparada dos perfis socioeconômico e político dos participantes das Conferências de Saúde (CS) e Conferências de Assistência Social (CAS)}

O mapa de pontos permite avaliar a associação entre as variáveis a partir da proximidade entre elas. O Gráfico 1 analisa a Conferência de Saúde e apresenta capacidade explicativa de $61 \%$. Ele nos possibilita traçar continuamente (a partir da dimensão 1 ) a evolução das etapas distrital (L1), municipal (L2), estadual, (L4) e nacional (L5) nessa conferência ${ }^{11}$.

\footnotetext{
${ }^{11}$ Diferente da CAS, na análise realizada, a CS não possui a etapa estadual (L3), somente os delegados desta etapa (L4). Isto se justifica pela ausência de dados sobre os participantes nessa etapa. O Conselho Estadual de Saúde de Minas Gerais não disponibilizou os dados sobre todos(as) os(as) delegados(as) representantes de Minas Gerais, somente sobre os(as) delegados(as) eleitos(as) para a etapa nacional.
} 
A opção por analisar as conferências em gráficos separados por política justificase por nos permitir identificar com maior clareza os perfis mais associados a cada escala.

Para entender a evolução nas etapas, a análise começará pela etapa distrital (L1), localizada no quadrante 4, à direita na dimensão 1 e abaixo na dimensão 2 . Seguirá para a etapa municipal (L2), localizada no centro do Gráfico 1, mas levemente deslocada para o quadrante 2. A etapa seguinte, a estadual (L4), está localizada à esquerda na dimensão 1 e acima na dimensão 2. Essa etapa diz respeito somente aos(às) delegados(as) eleitos(as) para a etapa nacional e não se refere a todos(as) os(as) delegados(as) da etapa estadual. A etapa nacional (L5) também está localizada à esquerda e abaixo no quadrante 3.

Ao avaliar a disposição dessas categorias no Gráfico 1, é possível afirmar que as etapas distritais e municipais assumem posições opostas às etapas estadual e nacional, ou seja, as categorias que guardam relação com as duas primeiras etapas da conferência são diferentes das categorias relacionadas às duas últimas etapas. A mudança de escala, portanto, impacta os perfis dos atores que seguem na Conferência de Saúde. Essa diferença ficará mais evidente na descrição das relações estabelecidas entre as etapas das conferências e as categorias mais próximas a elas. 


\section{Conferências de Saúde}

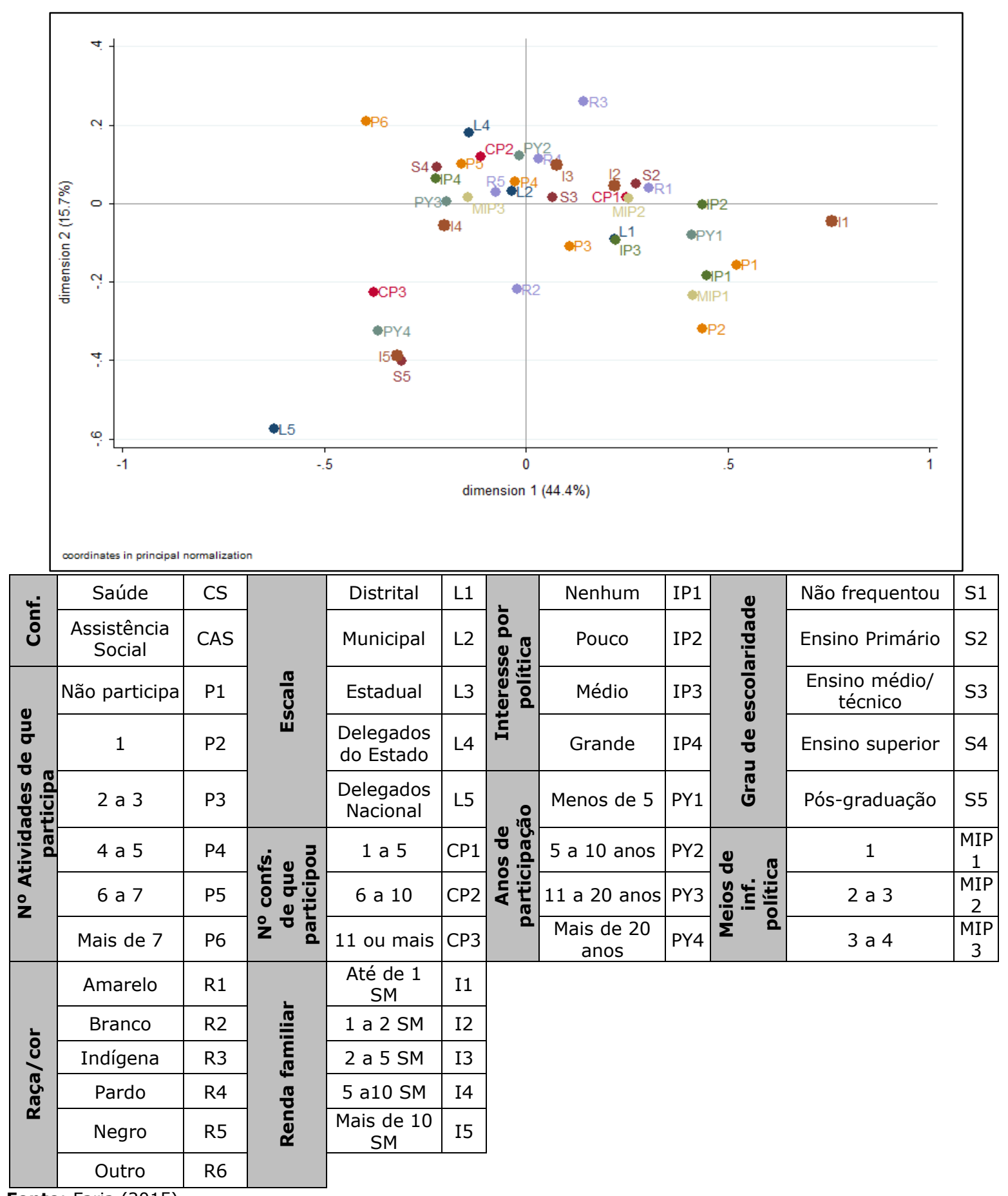

Fonte: Faria (2015). 
O Gráfico 2 analisa a Conferência de Assistência Social (CAS) e apresenta capacidade explicativa de 74\%. Diferentemente do Gráfico 1 (CS), nesse Gráfico 2 não podemos traçar continuamente (a partir da dimensão 1) a evolução das etapas das conferências. A etapa distrital (L1) está localizada no quadrante 3, à esquerda na dimensão 1 e abaixo na dimensão 2. A etapa municipal (L2) está localizada próxima do centro do Gráfico 2, abaixo da dimensão 2 e na dimensão 1, ligeiramente inclinada para a esquerda, portanto mais próxima da etapa distrital. A etapa estadual (L3) e a etapa estadualdelegados(as) (L4) encontram-se no quadrante 1, à direita na dimensão 1 e acima na dimensão 2. A etapa nacional (L5) está localizada no quadrante 4, à direita na dimensão 1 e abaixo na dimensão 2 .

Entretanto, como na saúde, a disposição assumida pelas categorias no Gráfico 2 nos permite afirmar que as etapas distritais e municipal (L1 e L2) assumem posições opostas às outras etapas da conferência, ou seja, as categorias mais associadas às primeiras etapas são diferentes das categorias próximas às etapas estadual (L3 ${ }^{12}$ e L4) e nacional (L5). A mudança de escala, portanto, também impacta os perfis dos atores que ascendem no processo conferencista da política de Assistência Social.

\footnotetext{
12 Para efeitos comparativos, L3 não será considerada na análise do Gráfico 2.
} 
Gráfico 2

Conferências de Assistência Social

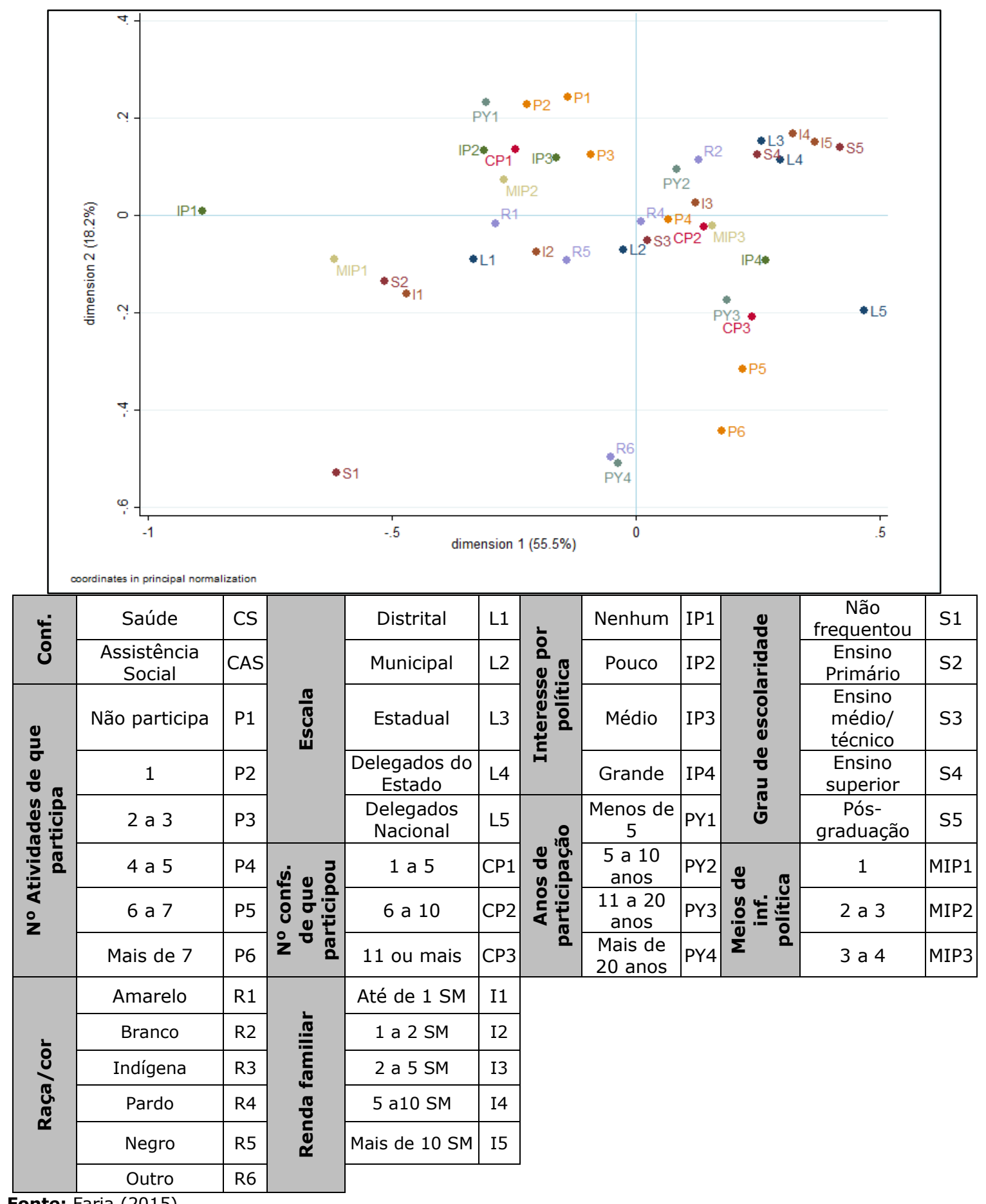

Fonte: Faria (2015). 
No Quadro 2 estão descritas as categorias relativas ao perfil socioeconômico e político mais próximas de cada etapa das conferências analisadas, bem como os dados descritivos relativos ao gênero e às faixas etárias.

Quadro 2

Descrição das categorias mais próximas de cada escala por tipo de conferência

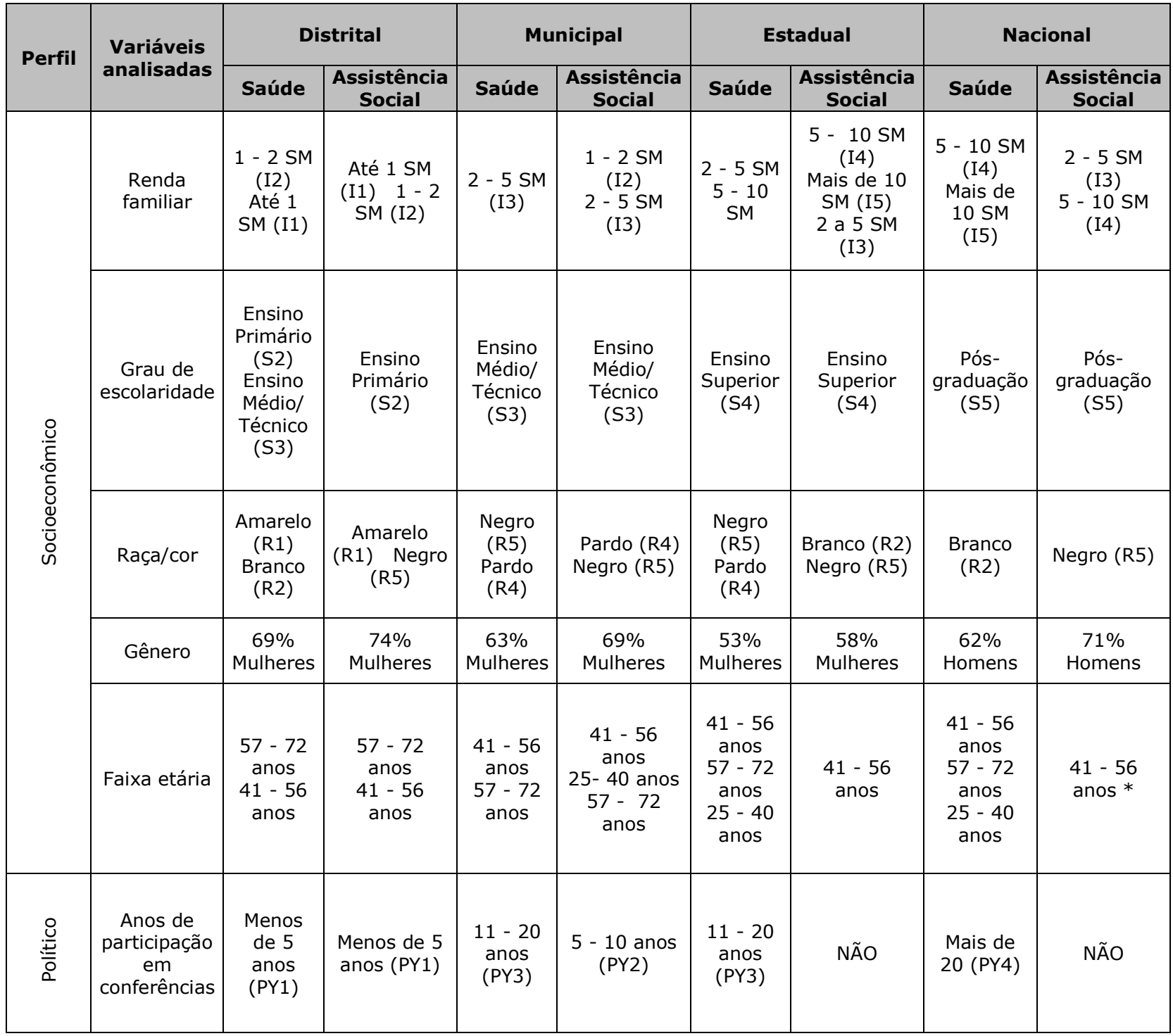




\begin{tabular}{|c|c|c|c|c|c|c|c|c|c|}
\hline \multirow{2}{*}{ Perfil } & \multirow{2}{*}{$\begin{array}{c}\text { Variáveis } \\
\text { analisadas }\end{array}$} & \multicolumn{2}{|c|}{ Distrital } & \multicolumn{2}{|c|}{ Municipal } & \multicolumn{2}{|c|}{ Estadual } & \multicolumn{2}{|c|}{ Nacional } \\
\hline & & Saúde & $\begin{array}{c}\text { Assistência } \\
\text { Social }\end{array}$ & Saúde & $\begin{array}{c}\text { Assistência } \\
\text { Social }\end{array}$ & Saúde & $\begin{array}{c}\text { Assistência } \\
\text { Social }\end{array}$ & Saúde & $\begin{array}{c}\text { Assistência } \\
\text { Social }\end{array}$ \\
\hline \multirow{5}{*}{$\frac{O}{\stackrel{O}{ \pm}}$} & $\begin{array}{c}\text { No de } \\
\text { atividades } \\
\text { de que } \\
\text { participa }\end{array}$ & $\begin{array}{c}2-3 \\
\text { (P3) } \\
\text { Não } \\
\text { participa } \\
(\text { P1) } 1 \\
(P 2)\end{array}$ & $2-3(P 3)$ & $4-5(P 4)$ & $4-5(P 4)$ & $\begin{array}{l}6-7 \text { (P5) } \\
\text { Mais de } 7 \\
\quad(P 6)\end{array}$ & $4-5(P 4)$ & NÃO & $\begin{array}{l}6-7(P 5) \\
\text { Mais de } 7 \\
\quad(P 6)\end{array}$ \\
\hline & $\begin{array}{c}\text { No de } \\
\text { conferências } \\
\text { de que já } \\
\text { participou }\end{array}$ & $\begin{array}{l}1-5 \\
(\mathrm{CP} 1)\end{array}$ & NÃO & $6-10(\mathrm{CP} 2)$ & $6-10(\mathrm{CP} 2)$ & $6-10(\mathrm{CP} 2)$ & NÃO & $\begin{array}{l}11 \text { ou } \\
\text { mais } \\
\text { (CP3) }\end{array}$ & $\begin{array}{l}11 \text { ou mais } \\
\text { (CP3) }\end{array}$ \\
\hline & \multirow{2}{*}{$\begin{array}{l}\text { Interesse } \\
\text { por política }\end{array}$} & $\begin{array}{l}\text { Nenhum } \\
\text { (IP1) }\end{array}$ & \multirow{2}{*}{$\begin{array}{l}\text { Pouco (IP2) } \\
\text { Médio (IP3) }\end{array}$} & \multirow{2}{*}{ Grande (IP4) } & \multirow{2}{*}{ Grande (IP4) } & \multirow{2}{*}{ Grande (IP4) } & \multirow{2}{*}{ NÃO } & \multirow{2}{*}{ NÃO } & \multirow{2}{*}{ Grande (IP4) } \\
\hline & & $\begin{array}{l}\text { Pouco } \\
\text { (IP2) }\end{array}$ & & & & & & & \\
\hline & $\begin{array}{c}\text { Meios de } \\
\text { informação } \\
\text { sobre } \\
\text { política }\end{array}$ & $\begin{array}{c}1 \\
(\mathrm{MIP} 1) \\
2-3 \\
(\mathrm{MIP} 2)\end{array}$ & $\begin{array}{c}1 \text { (MIP1) } \\
2-3 \text { (MIP2) }\end{array}$ & $\begin{array}{l}3-4(\text { MIP3) } \\
2-3(\text { MIP2) }\end{array}$ & $3-4$ (MIP3) & $3-4$ (MIP3) & NÃO & NÃO & NÃO \\
\hline
\end{tabular}

Fonte: Elaboração das autoras.

\section{Análise comparada dos dados}

Os dados sugerem que os perfis socioeconômico e político dos participantes das Conferências de Saúde (CS) e de Assistência Social (CAS) são, em Minas Gerais, semelhantes, mas variam por etapa.

A análise dos Gráficos 1 e 2 e da estatística descritiva mostra ainda que as categorias de valores mais baixos estão todas associadas às etapas distritais (L1), assim como as de valores mais altos estão mais associadas às etapas estadual e nacional ( $L 4$ e L5, respetivamente).

Como descrito no Quadro 2, o perfil mais associado às etapas distritais das duas conferências é composto por atributos como renda familiar baixa (até 1 salário mínimo (SM) e de 1 a 2 SM); escolaridade baixa (ensino fundamental e médio, sendo esse último mais associado à CS); interesse por política baixo (pouco e nenhum); e menor experiência participativa nas conferências atestada pela proximidade com as categorias "número de conferências de que participou" (de 1 a 5 conferências) e "tempo de participação nelas" (menos de 5 anos). 
Esse perfil reflete a realidade socioeconômica do município de Belo Horizonte (doravante $\mathrm{BH}$ ), onde $46,6 \%$ dos habitantes apresentam renda familiar de até 1 a 2 SM e $49 \%$ apresentam grau de escolaridade que varia do ensino fundamental $(20,5 \%)$ ao ensino médio $(28,5 \%)$ (IBGE-PNAD, 2011) $)^{13}$.

$\mathrm{Na}$ etapa municipal, os perfis mais associados mudam nas duas conferências. $A$ renda familiar mais associada sobe (de 2 a $5 \mathrm{SM}$ ) e o grau de escolaridade predominante passa a ser o ensino médio. Sobem igualmente todos os indicadores políticos: interesse por política cresce, alcançando o máximo; número de atividades políticas de que participam varia de 4 a 5 ; número de conferências em que participou e tempo de participação também aumentam - de 6 a 10 conferências e de 5 a 10 anos de participação, respectivamente.

O perfil socioeconômico descrito, embora diferente da etapa distrital, ainda guarda semelhança com o perfil dos habitantes do município onde quase um terço da população apresenta renda familiar que varia de 2 a 5 salários mínimos (27\%) e nível de escolaridade médio $(28,5 \%)$.

Nas etapas estadual e nacional, esses perfis mudam ainda mais. Na etapa estadual (L4), embora o atributo renda esteja ausente do Gráfico 1, a estatística descritiva mostra que a porcentagem daqueles que declararam renda familiar de 5 a 10 SM e acima de 10 SM aumenta. Na Conferência Estadual de Assistência Social (Ceas), além da proximidade com as faixas de renda familiar descritas, aparece também a faixa de 2 a 5 SM. No entanto, o nível de escolaridade mais próximo é, em ambas as conferências, ensino superior e pósgraduação e o perfil político mais associado é igualmente alto: participação em várias atividades políticas (de 4 a 7 e mais de 7 atividades). Aumentam também o número de conferências de que já participou (de 6 a 10 conferências) e o tempo de participação nestas (de 11 a 20 anos).

É nessa etapa que, pela primeira vez, cresce a porcentagem de homens em ambas as conferências, sem, contudo, ultrapassar a de mulheres (53\% para CS e $58 \%$ para CAS). Entretanto, na etapa nacional (L5), a porcentagem de delegados oriundos de Belo Horizonte ultrapassa a de delegadas $(62 \%$ e $71 \%$ de delegados nas CS e CAS, respectivamente). Esse dado ganha ainda mais relevância ao constatarmos o perfil de gênero do estado e da capital mineira, que apresentam predomínio de mulheres: $51 \%$ e $52 \%$, respectivamente.

O perfil dos delegados(as) da etapa nacional (L5) segue o mesmo padrão daqueles da etapa estadual: renda familiar, grau de escolaridade e perfil político altos. Mesmo quando há proximidade com renda familiar comparativamente mais baixa (de 2 a 5 SM), como é o caso das CAS, os indicadores de escolaridade, de engajamento cívico e de experiência nas conferências continuam altos.

\footnotetext{
13 Essas porcentagens resultam da soma daquelas encontradas na IBGE-PNAD (2011) para os intervalos de renda que compreendem de até $1 / 2$ SM a 2 SM e para os intervalos de anos de estudo que compreendem de 1 a 13 anos de estudo (IBGE-PNAD, 2011).
} 
Constata-se, portanto, que a seleção de delegados(as) em ambas as conferências está positivamente associada ao aumento da renda, da escolaridade, do interesse por política, do número de atividades políticas de que participam e dos anos de experiência nas conferências, mas negativamente associada aos níveis de renda e escolaridade dos habitantes do estado de Minas Gerais. Nesse caso, apenas 6,5\% desses habitantes possuem rendas familiares que variam de 5 a 10 SM e somente $2 \%$ apresentam renda entre mais de 10 e 20 SM. Assim também com escolaridade, apenas 15\% dos habitantes do estado possuem o ensino médio (IBGE-PNAD, 2011) ${ }^{14}$.

Uma vez que autodeclarados pardos e negros estão associados a todas as etapas, é possível afirmar que o perfil étnico dos(as) conferencistas não varia com a escala e reflete a realidade étnica tanto do estado quanto da capital mineira, que apresentam $59 \%$ e $58 \%$ de pardos e negros, respectivamente, de acordo com a declaração da população (IBGEPNAD, 2011). A exceção é a etapa nacional (L5) da Conferência de Saúde, em que encontramos mais participantes que se autodeclaram brancos(as) quando comparamos com a mesma etapa da CAS.

O perfil etário também não varia significativamente com a escala, mas é possível constatar a ausência de jovens em todas as etapas analisadas.

Como visto até aqui, exceto para os atributos relativos a etnia e idade, todos os demais atributos analisados mudam na medida em que há mudança territorial.

Os perfis mais associados às etapas distritais contrariam a literatura consagrada sobre o tema, que registra, em geral, um viés elitista da participação e, consequentemente, uma desigualdade de voz como resultado. Cidadãos com mais recursos socioeconômicos e políticos tendem a participar mais e, assim, influenciam mais os seus representantes e as decisões políticas (Verba, Schlozman e Brady, 1995, p. 186).

Nos casos analisados, o perfil socioeconômico mais associado às etapas distritais não se diferencia muito do perfil socioeconômico de quase a metade da população de $\mathrm{BH}$, embora se diferencie muito dos perfis mais associados às etapas estadual e nacional desse processo.

No que diz respeito ao perfil político, quando comparamos os atributos encontrados nessa etapa com os dados sobre o perfil político dos conselheiros municipais, estaduais e nacionais nessas mesmas áreas de política, percebemos que as/os conferencistas das etapas distritais apresentam atributos políticos e também socioeconômicos com valores mais baixos que os usualmente encontrados nesses outros arranjos participativos (Fuks, Perissinotto e Ribeiro, 2003; Santos Júnior, Ribeiro e Azevedo, 2004; Faria et al., 2010; Alencar et al., 2013).

\footnotetext{
14 Não encontramos dados sobre os atributos políticos para Belo Horizonte e Minas Gerais tais como aqueles trabalhados no artigo. Sabe-se, entretanto, que os conselheiros municipais e estaduais da saúde e da assistência social apresentam perfis socioeconômicos e políticos similares e/ou mais altos do que os/as conferencistas dessas mesmas etapas (Santos Júnior et al, 2004; Faria et al., 2012).
} 
Conselhos e conferências são arranjos participativos distintos no que diz respeito a função, periodicidade de suas reuniões ou regras para o recrutamento ${ }^{15}$. Dessa forma, o custo da participação nos conselhos é maior do que nas conferências, que ocorrem episodicamente e são mais abertas à participação dos afetados.

Ainda assim, é possível afirmar que as etapas distritais das conferências analisadas conseguem atrair perfis diferentes que evidenciam o seu caráter inclusivo nas etapas locais. Não obstante, quando mudamos a escala, constatamos uma mudança nos perfis aludidos. A partir da conferência distrital, esses perfis se aproximam, paulatinamente, daqueles encontrados nos conselhos, conforme ressaltado pela literatura supracitada. Todos os atributos individuais analisados - renda, escolaridade, vínculos com atividades políticas, interesse por política e experiência de participação na conferência - sobem com a mudança territorial das conferências.

Ante o processo crescente de elitização dos perfis analisados das(dos) conferencistas, vale a pena nos perguntarmos se e em que medida as regras que ordenam esses arranjos e/ou a ausência delas nos ajudam a explicar o padrão encontrado. Na seção abaixo avaliamos os perfis descritos à luz do desenho institucional das duas conferências analisadas.

\section{Desenho institucional das CS e das CAS}

O processo conferencista nas duas políticas analisadas começa nos locais territorialmente mais próximos dos cidadãos de Belo Horizonte. No caso da CS, no bairro, e no caso da CAS, no distrito ${ }^{16}$. A participação é, nesses níveis, aberta ao público.

A partir dessas etapas impõe-se uma dinâmica representativa cujos critérios são definidos pelas respectivas Comissões Organizadoras e publicados nos respectivos Regimentos Internos. Esses Regimentos são debatidos nas plenárias de abertura das duas conferências e podem ser modificados mediante discussão e voto dos(as) participantes.

As duas conferências apresentam critérios similares tanto de recrutamento, baseado na auto seleção dos(as) participantes, quanto de escolha dos(as) representantes,

\footnotetext{
15 Conselhos apresentam um caráter permanente e há uma continuidade dos seus processos discursivos e decisórios, enquanto as conferências são realizadas em intervalos de tempo maiores. Nos casos analisados, de 2 em 2 anos. As conferências apresentam ainda uma dimensão do controle social mais política, uma vez que são espaços onde acontece a mobilização da sociedade com intuito de avaliar a situação da política pública, tentando influenciar a agenda governamental, a partir do levantamento de demandas e indicações de prioridades. Os conselhos apresentam, por sua vez, uma dimensão mais técnica do controle social na medida em que são espaços formados por um número restrito de participantes com funções de fiscalizar, monitorar e acompanhar as ações governamentais.

16 Belo Horizonte é dividida em nove Administrações Regionais que abrigam os nove Distritos Sanitários. Estes são subdivididos em vários subdistritos. No caso da política de saúde, esses subdistritos possuem suas respectivas Comissões Locais de Saúde, que são as comissões responsáveis pela organização das Conferências Locais de Saúde no município. Essas comissões funcionam nos postos de saúde e nas Unidades de Pronto Atendimento (UPA). Esse tipo de organização ainda não existe em nenhuma outra área de política em Belo Horizonte. Por isso, a Conferência de Saúde é mais descentralizada territorialmente.
} 
baseados na divisão funcional de cada política, no tamanho do território e no número de participantes nessas etapas.

Como descrito nos Quadros 3 e 4, a partir das etapas locais nas CS e das etapas distritais nas CAS, a seleção dos(as) participantes até a etapa nacional é realizada pelos(as) delegados(as) através de processo eleitoral baseado em regras definidas pelo Regimento Interno (RI) e aprovadas na plenária inicial de cada etapa da conferência.

No que diz respeito à divisão funcional, o RI da CS prevê $50 \%$ de usuários, $25 \%$ de trabalhadores e $25 \%$ de representantes de governo e prestadores de serviços. No que diz respeito ao critério territorial, a partir da etapa distrital, cada unidade territorial é representada pelo tamanho da sua população.

No caso da CAS, a divisão funcional ocorre entre representantes da sociedade civil (50\%) e do governo (50\%). A sociedade civil é dividida em três segmentos: usuários, trabalhadores e entidades socioassistenciais. O governo é representado por gestores(as) da política de AS e de outras políticas que possuem interface com a política de assistência social, como as de educação, saúde, direitos do idoso.

Ao contrário da área de saúde, em que os usuários são positivamente discriminados, dado que $50 \%$ dos(as) eleitos(as) deverão pertencer a esse segmento, na área de assistência social o critério de representação discrimina positivamente o governo, na medida em que os $50 \%$ destinados à representação da sociedade civil são divididos entre os três segmentos mencionados.

Nas duas conferências existem cotas de participação previamente estabelecidas para os conselheiros que são considerados(as) delegados(as) natos(as) em cada escala. 
Quadro 3

Desenho institucional das Conferências de Saúde (2011)

\begin{tabular}{|c|c|c|c|c|}
\hline \multicolumn{2}{|c|}{ Etapas da conferência } & \multirow{2}{*}{$\begin{array}{c}\text { Participação } \\
\text { Critério de } \\
\text { participação }\end{array}$} & \multicolumn{2}{|l|}{ Representação } \\
\hline Escala & $\begin{array}{l}\text { Número de } \\
\text { conferências }\end{array}$ & & $\begin{array}{c}\text { Critérios para eleição dos } \\
\text { delegados(as) }\end{array}$ & $\begin{array}{c}\text { Comissão } \\
\text { organizadora }\end{array}$ \\
\hline Local & 159 & $\begin{array}{l}\text { Aberta para todos } \\
\text { os afetados }\end{array}$ & $\begin{array}{l}\text { Critérios baseados em (1) } \\
\text { infraestrutura local, (2) } \\
\text { experiência participativa e (3) } \\
\text { recursos disponíveis. Todos os } \\
\text { Centros de Saúde devem estar } \\
\text { representados. Paridade de } \\
50 \% \text { de usuários, } 25 \% \text { de } \\
\text { governo/prestadores de } \\
\text { serviços privados e } 25 \% \text { dos } \\
\text { trabalhadores da saúde. }\end{array}$ & $\begin{array}{l}\text { Secretaria } \\
\text { Municipal de } \\
\text { Saúde e } \\
\text { Comissão Local } \\
\text { de Saúde }\end{array}$ \\
\hline \multirow[b]{2}{*}{ Distrital } & \multirow[b]{2}{*}{9} & \begin{tabular}{|l|} 
Cidadãos - \\
delegados(as) \\
eleitos(as) em \\
cada região \\
\end{tabular} & $\begin{array}{l}\text { Critérios anteriores definidos } \\
\text { com base no tamanho da } \\
\text { população do distrito. }\end{array}$ & \multirow{2}{*}{$\begin{array}{l}\text { Secretaria } \\
\text { Municipal de } \\
\text { Saúde e } \\
\text { Conselho } \\
\text { Distrital de } \\
\text { Saúde }\end{array}$} \\
\hline & & \begin{tabular}{|l|} 
Conselheiros \\
distritais - \\
delegados(as) \\
natos(as) \\
Convidados \\
\end{tabular} & A paridade deve ser mantida. & \\
\hline \multirow[b]{2}{*}{ Municipal } & \multirow[b]{2}{*}{1} & \multirow{2}{*}{$\begin{array}{l}1724 \text { Cidadãos - } \\
\text { delegados(as) } \\
\text { eleitos(as) em } \\
\text { cada distrito } \\
\text { sanitário } \\
\text { Conselheiros } \\
\text { municipais - } \\
\text { delegados natos e } \\
\text { convidados }\end{array}$} & $\begin{array}{l}\text { Critérios anteriores definidos } \\
\text { com base no tamanho da } \\
\text { população do município }\end{array}$ & \multirow{2}{*}{$\begin{array}{l}\text { Secretaria } \\
\text { Municipal de } \\
\text { Saúde e } \\
\text { Conselho } \\
\text { Municipal de } \\
\text { Saúde }\end{array}$} \\
\hline & & & A paridade deve ser mantida. & \\
\hline \multirow[t]{2}{*}{ Estadual } & \multirow[t]{2}{*}{$\begin{array}{c}427 \\
\text { Conferências } \\
\text { municipais }\end{array}$} & $\begin{array}{l}\text { Cidadãos - } \\
\text { delegados(as) } \\
\text { eleitos(as) em } \\
\text { todo o estado } \\
\text { Conselheiros } \\
\text { estaduais - } \\
\text { delegados natos, } \\
\text { convidados e } \\
\text { palestrantes }\end{array}$ & $\begin{array}{l}\text { Critérios anteriores definidos: } \\
30 \% \text { dos delegados(as) são } \\
\text { igualmente divididos entre } \\
\text { todos os estados brasileiros ( } 27 \\
+ \text { DF); } 70 \% \text { dos delegados(as) } \\
\text { são divididos } \\
\text { proporcionalmente de acordo } \\
\text { com o Índice de Representação } \\
\text { com base no tamanho da } \\
\text { população brasileira. O número } \\
\text { final de delegados(as) por } \\
\text { estado deve ser um múltiplo de } \\
4 \text {. }\end{array}$ & \multirow[t]{2}{*}{$\begin{array}{l}\text { Secretaria } \\
\text { Estadual de } \\
\text { Saúde e } \\
\text { Conselho } \\
\text { Estadual de } \\
\text { Saúde }\end{array}$} \\
\hline & & & A paridade deve ser mantida. & \\
\hline
\end{tabular}




\begin{tabular}{|c|c|c|c|c|}
\hline \multicolumn{2}{|c|}{ Etapas da conferência } & \multirow{2}{*}{$\begin{array}{c}\text { Participação } \\
\text { Critério de } \\
\text { participação }\end{array}$} & \multicolumn{2}{|c|}{ Representação } \\
\hline Escala & $\begin{array}{l}\text { Número de } \\
\text { conferências }\end{array}$ & & Escala & $\begin{array}{l}\text { Número de } \\
\text { conferências }\end{array}$ \\
\hline Nacional & $\begin{array}{c}4.347 \\
\text { conferências } \\
\text { municipais e } \\
27 \\
\text { conferências } \\
\text { estaduais }\end{array}$ & $\begin{array}{l}\text { 3.694 divididos por } \\
3.212 \\
\text { delegados(as) } \\
\text { eleitos(as) } \\
372 \\
\text { representantes de } \\
\text { organizações e } \\
\text { instituições } \\
\text { nacionais } \\
\text { Conselheiros } \\
\text { nacionais - } \\
\text { delegados natos } \\
\text { Convidados } \\
\text { Palestrantes }\end{array}$ & Não se aplica. & $\begin{array}{l}\text { Ministério da } \\
\text { Saúde e } \\
\text { Conselho } \\
\text { Nacional de } \\
\text { Saúde }\end{array}$ \\
\hline
\end{tabular}

Fonte: Elaboração das autoras.

Quadro 4

Desenho institucional das Conferências de Assistência Social (2011)

\begin{tabular}{|c|c|c|c|c|}
\hline \multicolumn{2}{|c|}{ Etapas da conferência } & \multirow{2}{*}{$\begin{array}{l}\text { Participação } \\
\text { Critério de } \\
\text { participação }\end{array}$} & \multicolumn{2}{|c|}{ Representação } \\
\hline Escala & $\begin{array}{l}\text { Número de } \\
\text { conferências }\end{array}$ & & $\begin{array}{c}\text { Critérios para eleição dos } \\
\text { delegados(as) }\end{array}$ & $\begin{array}{c}\text { Comissão } \\
\text { organizadora }\end{array}$ \\
\hline $\begin{array}{l}\text { Pré- } \\
\text { conferência }\end{array}$ & 9 & $\begin{array}{l}\text { Aberta para todos os } \\
\text { afetados pela política. }\end{array}$ & $\begin{array}{l}\text { Será eleito(a) } 1 \text { delegado(a) } \\
\text { para cada } 3 \text { participantes } \\
\text { credenciados nas pré- } \\
\text { conferências. }\end{array}$ & $\begin{array}{l}\text { Conselho } \\
\text { Municipal de } \\
\text { Assistência } \\
\text { Social de Belo } \\
\text { Horizonte }\end{array}$ \\
\hline \multirow[b]{3}{*}{ Municipal } & \multirow[b]{3}{*}{1} & $\begin{array}{l}\text { Cidadãos-delegados(as) } \\
\text { ( } 50 \% \text { sociedade civil - } \\
\text { usuários, trabalhadores e } \\
\text { entidades - e } 50 \% \\
\text { governo) }\end{array}$ & \multirow[t]{2}{*}{$\begin{array}{l}\text { Delegados(as) eleitos(as) } \\
\text { com base no tamanho da } \\
\text { população dos municípios. }\end{array}$} & \multirow[b]{3}{*}{$\begin{array}{l}\text { Secretaria } \\
\text { Municipal } \\
\text { Adjunta de } \\
\text { Assistência } \\
\text { Social e } \\
\text { Conselho } \\
\text { Municipal de } \\
\text { Assistência } \\
\text { Social }\end{array}$} \\
\hline & & \multirow[b]{2}{*}{$\begin{array}{l}1 \text { delegado(a) para cada } \\
3 \text { participantes } \\
\text { credenciados nas pré- } \\
\text { conferências, } \\
\text { Delegados(as) natos - } \\
\text { conselheiros municipais } \\
\text { de assistência social, } 1 \\
\text { delegado(a) do Ministério } \\
\text { Público do estado de } \\
\text { Minas Gerais, } 1 \\
\text { delegado(a) da União } \\
\text { dos Conselhos da Grande } \\
\text { BH, } 1 \text { delegado(a) para } \\
\text { cada autarquia, empresa } \\
\text { pública, órgãos diretos e } \\
\text { indiretos da } \\
\text { administração municipal } \\
\text { e secretaria. }\end{array}$} & & \\
\hline & & & $\begin{array}{l}\text { Cidadãos-delegados(as) } \\
\text { ( } 50 \% \text { sociedade civil - } \\
\text { usuários, trabalhadores e } \\
\text { entidades - e } 50 \% \text { governo) } \\
12 \text { delegados(as): } 6 \text { do } \\
\text { governo - sendo } 4 \text { do } \\
\text { órgão gestor e } 2 \text { de outras } \\
\text { secretarias; } \\
6 \text { da sociedade civil: } \\
2 \text { representante do conjunto } \\
\text { dos usuários } \\
2 \text { representantes de } \\
\text { entidades de assistência } \\
\text { social; } \\
2 \text { representantes de } \\
\text { trabalhadores da área }\end{array}$ & \\
\hline
\end{tabular}




\begin{tabular}{|c|c|c|c|c|}
\hline \multicolumn{2}{|c|}{ Etapas da conferência } & \multirow{2}{*}{$\begin{array}{c}\text { Participação } \\
\text { Critério de } \\
\text { participação }\end{array}$} & \multicolumn{2}{|c|}{ Representação } \\
\hline Escala & $\begin{array}{l}\text { Número de } \\
\text { conferências }\end{array}$ & & Escala & $\begin{array}{l}\text { Número de } \\
\text { conferências }\end{array}$ \\
\hline Estadual & $\begin{array}{c}50 \\
\text { conferências } \\
\text { municipais e } \\
24 \\
\text { conferências } \\
\text { regionais }\end{array}$ & $\begin{array}{l}1.000 \text { delegados(as) } \\
\text { eleitos(as) nas } \\
\text { conferências municipais e } \\
\text { encontros regionalizados, } \\
40 \text { delegados(as) } \\
\text { natos(as) - conselheiros } \\
\text { estaduais de Assistência } \\
\text { Social e } 88 \text { convidados. }\end{array}$ & $\begin{array}{l}\text { Cidadãos-delegados(as) } \\
\text { (50\% sociedade civil - } \\
\text { usuários, trabalhadores e } \\
\text { entidades - e 50\% governo) }\end{array}$ & $\begin{array}{l}\text { Conselho } \\
\text { Estadual de } \\
\text { Assistência } \\
\text { Social e } \\
\text { Secretaria de } \\
\text { Estado de } \\
\text { Desenvolvimento } \\
\text { Social }\end{array}$ \\
\hline Nacional & $\begin{array}{c}27 \\
\text { conferências } \\
\text { estaduais }\end{array}$ & $\begin{array}{l}\text { Cidadãos-delegados } \\
\text { (50\% sociedade civil - } \\
\text { usuários, trabalhadores e } \\
\text { entidades - e } 50 \% \\
\text { governo) } \\
36 \text { representantes do } \\
\text { Conselho Nacional de } \\
\text { Assistência Social, } 146 \\
\text { delegados(as) oriundos } \\
\text { dos conselhos estaduais, } \\
1.150 \text { delegados(as) } \\
\text { participantes das } \\
\text { conferências municipais. }\end{array}$ & Não se aplica. & $\begin{array}{l}\text { Ministério do } \\
\text { Desenvolvimento } \\
\text { Social e } \\
\text { Conselho } \\
\text { Nacional de } \\
\text { Assistência } \\
\text { Social }\end{array}$ \\
\hline
\end{tabular}

Fonte: Elaboração das autoras.

O perfil socioeconômico e político mais homogêneo dos participantes das etapas distritais pode ser explicado pelas regras de recrutamento. De um modo geral, a literatura mostra que arranjos participativos apoiados em assembleias abertas ao público, cujo recrutamento assume características mais passivas, apresentam maior dificuldade de expandir a rede de participantes e de incluir perfis mais plurais. Dado que a mobilização ocorre na e pela própria rede de atores da política, corre-se o risco de manter sempre o mesmo perfil daqueles que já participam (Fung, 2006; Ryfe e Stalburg, 2012; Ryan e 
Smith, 2014).

Se a estratégia de recrutamento explica a homogeneidade dos perfis mais associados, ela não consegue explicar a capacidade de mobilização das duas conferências e as suas diferenças: a CS atrai $15 \%$ de participantes que ainda não haviam participado da conferência e a CAS atrai 7\%, como atestam os dados da Tabela 2:

Tabela 2

Primeira vez que participou em conferências da política de referência ${ }^{17}$

\begin{tabular}{|l|c|c|}
\hline \multicolumn{3}{|c|}{ Conferências de políticas públicas } \\
\hline Participação em conferências & Saúde & Assistência social \\
\hline Participou pela primeira vez & $15 \%$ & $7 \%$ \\
\hline Participava antes & $85 \%$ & $93 \%$ \\
\hline NS/NR & $0 \%$ & $0 \%$ \\
\hline Total & 337 & 392 \\
\hline
\end{tabular}

Fonte: Faria (2015).

Nesse caso, nossa hipótese é de que a diferença de recursos organizacionais explica a maior capacidade da CS em atrair "novos(as)" participantes. As duas áreas de políticas contam com uma rede de conselhos presente em quase todos os municípios brasileiros, além de equipamentos públicos como postos de saúde e Centros de Referências da Assistência Social (CRAS) que funcionam como transmissores de informações (Quadro 5). Entretanto, a política de saúde apresenta uma trajetória participativa mais antiga, possui uma Comissão Organizadora mais estruturada ${ }^{18}$ e é muito mais organizacionalmente descentralizada do que a política de assistência social. A área de saúde possui Conselhos Locais e distritais distribuídos em todas as unidades de saúde de Belo Horizonte que atuam na divulgação e na mobilização das atividades da área.

Os dados do Quadro 5 mostram que os Conselhos Locais, os postos de saúde e os CRAS constituem os meios mais citados para obter informações sobre as distintas etapas das conferências, principalmente sobre as etapas distrital e municipal:

17 Tal dado foi calculado a partir do ano que o respondente disse ter participado pela primeira vez da conferência.

18 Nos decretos de convocação e em alguns RI das conferências está estabelecido que essas comissões apresentam, dentre outras funções, a de estimular, organizar e promover a divulgação e a mobilização das conferências. 


\section{Fontes de informações sobre as conferências}

\begin{tabular}{|c|c|c|c|c|}
\hline $\begin{array}{c}\text { Política } \\
\text { pública }\end{array}$ & Distrital & Municipal & Estadual & Nacional \\
\hline Saúde & $\begin{array}{c}\text { Conselho } \\
\text { Local } \\
\text { Posto de } \\
\text { saúde }\end{array}$ & $\begin{array}{c}\text { Conselho Local } \\
\text { Posto de saúde } \\
\text { Conselho } \\
\text { Municipal }\end{array}$ & $\begin{array}{c}\text { Conselho } \\
\text { Municipal }\end{array}$ & $\begin{array}{c}\text { Conselho Municipal } \\
\text { Conselho Estadual }\end{array}$ \\
\hline $\begin{array}{c}\text { Assistência } \\
\text { social }\end{array}$ & $\begin{array}{c}\text { Conselho } \\
\text { Local } \\
\text { Cras }\end{array}$ & $\begin{array}{c}\text { Conselho Local } \\
\text { Cras } \\
\text { Conversas } \\
\text { informais }\end{array}$ & $\begin{array}{c}\text { Conselho } \\
\text { Municipal } \\
\text { Conversas } \\
\text { informais } \\
\text { Conselho } \\
\text { Local }\end{array}$ & Meios de comunicação em geral \\
Conselho Municipal \\
\hline
\end{tabular}

Fonte: Faria (2015).

Os dados relativos aos perfis mais associados às demais etapas das conferências também podem ser explicados pelas regras desses arranjos, que, nesses casos, são as regras de seleção, ou seja, as relativas ao processo representativo das duas conferências.

Os Quadros 3 e 4 mostram claramente a inexistência de qualquer regra que assegure a paridade de gênero e/ou étnica, a pluralidade socioeconômica, política e de faixa etária, embora existam cotas para os(as) conselheiros(as) em todas as etapas.

Sendo assim, a maior participação das mulheres nas etapas distritais e municipais pode estar mais vinculada ao caráter territorial e, consequentemente, ao menor custo da participação nesses locais do que às regras que discriminam positivamente a participação das mulheres, pelo menos até as conferências de 2015.

A pesquisa de campo constatou que a proximidade das conferências distritais e municipais com o local de moradia, a carência de infraestrutura, como creches, bem como o incentivo para participar dado às mulheres que trabalham na área, facilitam a participação destas em detrimento de outras. Mulheres representantes dos segmentos trabalhadores e gestores ascendem mais na escala do que as mulheres representantes de usuários. Gestoras e trabalhadoras possuem incentivos diferenciados para participar das conferências, uma vez que para esses segmentos a participação conta como atividade de trabalho (Faria e Lins, 2013).

Mudanças nas regras da CS de 2015, que passaram a garantir representação paritária de gênero na etapa estadual, podem promover, ao longo do tempo, mudanças no perfil descrito e, consequentemente, maior influência nas decisões alcançadas. A ausência das mulheres nos espaços de decisão acarreta, como bem mostra a literatura sobre o tema, prejuízo na expressão e na efetivação de suas necessidades, interesses e propostas (Phillips, 1995).

Lüchmann, Almeida e Gimenes (2016) encontram padrões similares de representação de gênero ao analisarem a participação das mulheres nos conselhos gestores (assistência social, saúde e meio ambiente) por escala. A explicação para a 
presença menor das mulheres nas etapas territoriais superiores dos conselhos avaliados, notadamente na etapa nacional, apoia-se, entretanto, mais no tipo de associativismo presente em cada política do que nas regras de seleção propriamente ditas. Embora instigante a relação estabelecida para as inovações em análise, insistimos na hipótese sugerida de que a reflexão sobre as regras de seleção e suas possíveis mudanças impactaria o perfil de gênero encontrado na medida em que as cotas, ou medidas similares, assegurariam maior presença de mulheres nessas etapas, independentemente da associação de origem.

No caso da política de assistência social (AS), não constatamos nenhuma mudança nos regimentos que afetasse os perfis analisados. Embora o Conselho Nacional de AS tenha reconhecido a importância da participação dos adolescentes nas Conferências de Assistência Social e tenha recomendado publicamente a participação dos jovens, tal reconhecimento não redundou em nenhuma mudança normativa relativa ao recrutamento e à seleção dos participantes.

A ausência de jovens nesses espaços pode também ser explicada pela falta de incentivos à sua participação ${ }^{19}$. Em Minas Gerais, por exemplo, a candidatura de uma adolescente a delegada para a etapa nacional na Ceas de 2011 foi contestada e gerou um intenso debate entre candidatos e coordenadores sobre a validade dessa iniciativa. Pesquisas revelam o mesmo padrão para as jovens mulheres nas Conferências de Políticas de Mulheres no estado em suas diferentes edições (Silva, 2015).

Seguindo a mesma tendência constatada na literatura nacional e internacional, as conferências aqui analisadas apresentam um processo paulatino de elitização que compromete a pluralidade dos perfis dos(as) participantes, notadamente aqueles mais associados às escalas mais altas. Essa dinâmica não apresenta ainda perspectivas de mudança que poderiam derivar do debate coletivo das regras tradicionais de representação e, consequentemente, da sua prática.

\section{Escala e inclusão política nas conferências de saúde e assistência social}

Analisamos neste artigo a capacidade de inclusão política das CPPs por meio da investigação do perfil socioeconômico e político daqueles que são recrutados para participar

\footnotetext{
19 Pesquisa realizada pela Secretaria Nacional da Juventude sobre "o perfil e a opinião dos jovens brasileiros", entre abril e maio de 2013, mostra que $46 \%$ dos respondentes consideram "a participação e a mobilização nas ruas, bem como as ações diretas, formas de participação mais potentes para melhorar o Brasil". Conselhos e conferências não aparecem nas principais formas de atuação associativa desses mesmos jovens, embora $35 \%$ deles mencionassem essas arenas como aquelas que podem contribuir para mudar o Brasil (Brasil, SNJ, 2013, p. 38). Uma vez que as regras das conferências analisadas não discriminam faixas etárias, a preferência por outro tipo de participação e também os possíveis problemas no incentivo para participar e sair delegado podem ser fatores explicativos para a ausência dos jovens nas conferências analisadas. Além das formas de participação, uma outra hipótese a ser considerada é a própria área de política que, diferente das áreas de educação e juventude, por exemplo, atrai menos esse segmento populacional, embora apresente programas para os jovens.
} 
desses arranjos, assim como daqueles que são selecionados como seus delegados(as)representantes. Dado que as conferências são arranjos participativos nacionalizados, analisar quem entra e quem ascende importa para atestar o quão plurais e representativos esses espaços estão se tornando em um contexto marcado por seu aumento numérico e temático.

Além do estudo do perfil socioeconômico e político dos(as) participantes que entram e são selecionados(as) em cada escala das conferências, buscamos analisar também as regras que ordenam essas inovações e suas possíveis mudanças.

Se a literatura sobre o tema aponta para a persistente desigualdade de influência tanto na participação quanto na representação, decorrente das assimetrias organizacionais, informacionais e/ou econômicas dos atores sociais, apostamos que o debate em torno dessas regras e as mudanças que ele pode ensejar por meio de um processo que envolva "reflexividade institucional" podem impulsionar a abrangência inclusiva desses arranjos, tornando-os ainda mais democráticos.

A análise empreendida mostrou que os perfis socioeconômico e político mais associados às etapas distritais são comparativamente mais baixos do que aqueles que ascendem nas conferências e similares ao perfil socioeconômico de parte da população de Belo Horizonte e de Minas Gerais (IBGE-PNAD, 2011). Mostrou também que as duas conferências foram capazes de incluir novos atores: participantes que reportaram ainda não ter participado das conferências até 2011.

Há diferenças entre as conferências analisadas, que foram atribuídas ao desenho institucional e aos recursos - organizacional e político - de cada área. Embora apresentem um desenho muito similar no que diz respeito à participação e ao controle social, a trajetória das políticas é diferente. Ambas as conferências são descentralizadas e contam com uma rede de arranjos participativos e de serviços que ajudam na divulgação e no recrutamento dos participantes. Não obstante, na área de saúde, essa rede, formada no início dos anos 1990, encontra-se mais institucionalizada e territorialmente mais descentralizada do que na área de AS, que só recentemente criou as Comissões Locais de Assistência Social, consideradas, no caso da saúde, como fontes importantes de recrutamento de novos atores nessas políticas.

Além dos perfis comparativamente mais baixos associados à etapa distrital e da presença de "novos" atores que atestam a inclusão política promovida pelas inovações analisadas, mostramos também que, em Minas Gerais, quando o mecanismo de representação se impõe com a mudança de escala, os perfis aludidos mudam, tornandose, além de homogêneos, mais elitistas. A dinâmica representativa, centrada exclusivamente em critérios territoriais e populacionais, explica a dominância desse tipo de perfil (Phillips, 1995).

Sugerimos, assim, que mudanças nos critérios de representação podem vir a favorecer a pluralização dos perfis analisados, trazendo para as etapas estaduais e nacionais mais representantes com perfis socioeconômico e político similares àqueles que 
chegam à porta de entrada dessas conferências. Embora a dinâmica reflexiva em torno desses critérios pareça não ter ocorrido, acreditamos que essa estratégia, aliada àquelas que garantem capacidade de vocalização das(os) participantes com menor experiência participativa, pode contribuir para o aumento do potencial inclusivo desses arranjos ao garantir a presença e a influência dos grupos excluídos em todo o processo conferencista, não só no nível local, mas também nos estaduais e nacional.

Cláudia Feres Faria - Universidade Federal de Minas Gerais, Departamento de Ciência Política. E-mail: <cfaria@fafich.ufmg.br>.

Isabella Lourenço Lins - Universidade Federal de Minas Gerais, Departamento de Ciência Política. E-mail: <belalourenco_lins@hotmail.com>.

\section{Referências bibliográficas}

AbeRs, R. N.; KeCK, M. E. "Mobilizing the State: the erratic partner in Brazil's participatory water policy". Politics and Society, vol. 37, n², 289-314, 2009.

AlenCAR, J., et al. "Participação social e desigualdades nos Conselhos Nacionais". Sociologias, vol. $15, \mathrm{n}^{\circ} 32$, p. 112-146, 2013.

ALMEIDA, D. R. Representação política e conferências: estabelecendo uma agenda de pesquisa. In: Avritzer, L.; SouzA, C. H. L. (orgs.). Conferências nacionais: atores, dinâmicas participativas e efetividades. Brasília: Ipea, 2013.

Avritzer, L.; SouzA, C. H. L. (orgs.). Conferências nacionais: atores, dinâmicas participativas e efetividades. Brasília: Ipea, 2013.

Belo Horizonte. Regimento Interno da III Conferência Estadual de Políticas para as Mulheres. Belo Horizonte, 2011a.

Horizonte, 2011b.

Regimento Interno da VII Conferência Estadual de Saúde de Minas Gerais. Belo

Biroli, F. "Divisão sexual do trabalho e democracia". Dados, vol. 59, n³, p. 719-754, 2016.

Bohman, J. Public deliberation. Pluralism, complexity and democracy. The Cambridge: MIT Press, 1996.

BRASIL, SNJ. Secretaria Nacional da Juventude. Pesquisa nacional sobre "Perfil e opinião dos jovens brasileiros 2013", nov. 2013.

BRAsíliA. Regimento Interno da III Conferência Nacional de Política para as Mulheres. Brasília, SNPM, 2011a. Saúde, 2011b.

Regimento Interno da XIV Conferência Nacional de Saúde. Brasília, Conselho Nacional de

Couto, B. R., et al. (orgs.). O Sistema Único de Assistência Social no Brasil: uma realidade em movimento. São Paulo: Cortez, 2011. 
CunhA, E. S. M. Conferências de políticas públicas e inclusão participativa. In: AvrITZER, L.; SouzA, C. H. L. (orgs.). Conferências nacionais: atores, dinâmicas participativas e efetividades. Brasília: Ipea, 2013.

DAHL, R. A. On democracy. New Haven: Yale University Press, 2000.

On political equality. New Haven \& London: Yale University Press, 2006.

Downs, A. Uma teoria econômica da democracia. São Paulo: Edusp, 1999.

FARIA, C. F. "Perfil e opinião dos atores sobre as conferências distritais, municipais e estaduais de políticas públicas em Minas Gerais". Belo Horizonte: Fapemig - Relatório de pesquisa, 2015.

FARIA, C. F., et al. "Conselhos estaduais de políticas públicas: atores, regras e dinâmicas decisórias". Belo Horizonte: Fapemig - Relatório de pesquisa, 2010.

. Conferências locais, distritais e municipais de saúde: mudança de escala e formação de um sistema participativo, representativo e deliberativo de políticas públicas. Texto para discussão (Ipea, Brasília), vol. 1.727, p. 7-73, 2012.

FARIA, C. F.; LINS, I. L. Participação e deliberação nas Conferências de Saúde: do local ao nacional. In: AVritzer, L.; SouzA, C. H. L. (orgs.). Conferências nacionais: atores, dinâmicas participativas e efetividades. Brasília: Ipea, 2013.

FARiA, C. F.; Petinelli, V. S.; Lins, I. L. "Conferências de políticas públicas: um sistema integrado de participação e deliberação?". Revista Brasileira de Ciência Política, vol. 7, p. 249-284, 2011.

FuKS, M.; Perissinotto, R.; Ribeiro, E. A. "Cultura política e desigualdade: o caso dos conselhos municipais de Curitiba". Revista de Sociologia e Política, n²1, p. 125-145, 2003.

FUNG, A. Receitas para esferas públicas: oito desenhos institucionais e suas consequências. In: Coelho, V. S. P; Nobre, M. (orgs.). Participação e deliberação. Teoria democrática e experiências institucionais no Brasil contemporâneo. São Paulo: Editora 34, 2004.

n०1, p. 66-75, 2006.

GreenACRE, M. Correpondence analysis in practice. 2a ed. Champman \& Hall/CRC, 2007.

GreenACRE, M.; Blaisus, J. (eds.). Multiple correspondence analysis and related methods. Champman \& Hall/CRC, 2006.

IBGE-PNAD. Pesquisa Nacional de Amostra Domiciliar (PNAD). Rio de Janeiro: IBGE, 2011. Disponível em:

<http://www.ibge.gov.br/home/estatistica/populacao/trabalhoerendimento/pnad2011/default_sinte se.shtm>. Acesso em: 17 ago. 2015.

LANDWEHR, C. "Democratic meta-deliberation: towards reflective institutional design". Political Studies, vol. 63, p. 38-54, 2015.

Lavalle, A.; Castello, G. "Sociedade civil, representação e a dupla face da accountability: cidade do México e São Paulo". Caderno CRH, vol. 21, n 52, p. 67-86, jan./abr., 2008.

LÜCHMANN L. H. H. "A representação no interior das experiências de participação". Lua Nova, n 70, p. 139-170, 2007. 
LÜChMANN L. H. H.; ALmeidA, C.; Gimenes, É. R. "Gênero e representação política nos conselhos gestores no Brasil". Dados, vol. 59, n 3, p. 789-822, 2016.

MANIN, B. The principles of representative government. Cambridge: Cambridge University Press, 1995.

MCCARTHY, J. D.; ZALD, M. N. "Resource mobilization and social movements: a partial theory". American Journal of Sociology, vol. 82, n 6, 1977.

MigueL, L. F. Democracia e representação: territórios em disputa. São Paulo: Editora Unesp, 2014.

PHILLIPS, A. The politics of presence. Oxford: Clarendon Press, 1995.

POGREBINSCHI, T.; SANTOS, F. "Participação como representação: o impacto das conferências nacionais de políticas públicas no Congresso Nacional". Dados, vol. 54, n 3, p. 259-305, 2011.

Ramos, A.; Faria, C. F. "Las conferencias de políticas públicas en Brasil". Revista Española de Ciencia Política, vol. 32, p. 43-63, 2013.

Ryan, M.; SMith, G. Defining mini-publics. In: Gronlund, K.; Bachtiger, A.; Setala, M.

(eds.). Deliberative mini-publics: involving citizens in the democratic process. Colchester, GB: ECPR Press, p. 9-26, 2014.

RyFe, D. M.; StalbuRg, B. The participation and recruitment challenge. In: NABATCHI, T., et al. (eds.). Democracy in motion: evaluating the practice and impact of deliberative civic engagement.

Oxford/New York: Oxford University Press, p. 43-59, 2012.

SANTOS, F. M.; POGREBINSCHI, T. Entre representação e participação: as conferências nacionais e o experimentalismo democrático brasileiro. Instituto Universitário de Pesquisas do Rio de Janeiro (Iuperj): Projeto "Pensando o Direito" da Secretaria de Assuntos Legislativos do Ministério da Justiça (SAL/MJ) e do Programa das Nações Unidas para o Desenvolvimento (PNUD), 2010.

SAntos JúnioR, O. A.; Ribeiro, L. C. Q.; Azevedo, S. (orgs.). Governança democrática e poder local: a experiência dos conselhos municipais no Brasil. Rio de Janeiro: Revan/Fase, 2004.

SCHUMPETER, J. Capitalismo, socialismo e democracia. Rio de Janeiro: Fundo de Cultura, 1961.

SiLVA, A. C. F. "Ampliando os limites do Estado: conflito e cooperação entre agentes estatais e da sociedade civil na luta por inclusão das mulheres jovens na agenda governamental". Dissertação de Mestrado. Programa de Pós-Graduação em Ciência Política. Universidade Federal de Minas Gerais, Belo Horizonte, 2015.

SмITH, G. Democratic innovations. Designing institutions for citizen participation. Cambridge: Cambridge University Press, 2009.

SouzA, C., et. al. "Ampliação da participação na gestão pública: um estudo sobre conferências nacionais realizadas entre 2003 e 2011". Relatório de pesquisa, Ipea, 2013.

TeiXeirA, A. C. T.; SouZA, C. H. L.; LimA, P. P. F. "Arquitetura da participação no Brasil: uma leitura das representações políticas em espaços participativos nacionais". Texto para discussão, n 1735 . Ipea, Rio de Janeiro, 2012.

VerBA, S.; SChlozman, K. L.; BRADY, H. E. Voice and equality: civic voluntarism in American politics. Cambridge: Harvard University Press, 1995.

Young, I. M. Inclusion and democracy. Oxford: Oxford University Press, 2002. 


\section{Resumo}

Inclusão política? Recrutamento e seleção de atores nas conferências de políticas públicas

O artigo avalia comparativamente a capacidade inclusiva das Conferências de Saúde e de Assistência Social realizadas em 2011, em Minas Gerais, por meio de uma estratégia analítica que envolve três passos distintos. Através do survey realizado com 729 participantes destas Conferências, analisa-se (1) quem são os participantes destas Conferências, (2) o impacto da mudança de escala no perfil socioeconômico e político destes participantes e (3) as regras referentes ao recrutamento (quem pode participar) e à eleição dos(as) delegados(as)-representantes nestas inovações. $\mathrm{O}$ artigo constata que, embora as Conferências de Políticas Públicas tenham como objetivo incluir nacionalmente novas vozes ao processo de discussão e decisão das políticas públicas as quais elas estão vinculadas, este processo ocorre majoritariamente nas etapas locais, mas não em suas etapas superiores. $\mathrm{O}$ artigo ainda sugere que mudanças nas regras de seleção das conferências analisadas podem contribuir para mudar este cenário.

Palavras-chave: conferências de políticas públicas; inclusão política; recrutamento; seleção e regras institucionais

\section{Abstract \\ Political Inclusion? Recruitment and selection of actors in the public policy conferences}

This article evaluates comparatively the capacity of inclusion of the health and Social Assistance Conferences held in 2011 in Minas Gerais, through an analytical strategy that involves three distinct steps. Through a survey of 729 participants of these Conferences, this article comparatively analyzes: (1) who the participants of these Conferences are; (2) whether or not the impact of scale changes the participants' socioeconomic and political profiles; and (3) what the PPC rules are concerning recruitment (who can participate) and representative processes (how are the delegate-representatives selected). The article found that these innovations include new actors, but they are not able to scale up and to get the higher scales, at least in Minas Gerais. To deal with these constraints, this article suggests the discussion and the changes on the PPC rules.

Keywords: public policy conferences; political inclusion scales; recruitment and selection; institutional design

\section{Resumen}

¿Inclusión política? Reclutamiento y selección de actores en las conferencias de políticas públicas

El artículo evalúa comparativamente la capacidad inclusiva de las Conferencias de Salud y de Asistencia Social realizadas en 2011, en Minas Gerais, por medio de una estrategia analítica que involucra tres pasos diferentes. A través de la encuesta realizada con 729 participantes de estas Conferencias, se analiza (1) quienes son los participantes de estas Conferencias, (2) el impacto del cambio de escala en el perfil socioeconómico y político de estos participantes y (3) las reglas referentes al reclutamiento (quién puede participar) y a la elección de los delegados-representantes en estas innovaciones. El artículo constata que, aunque las Conferencias de Políticas Públicas tienen como objetivo incluir nacionalmente voces nuevas en el proceso de discusión y decisión de las políticas públicas a las que están vinculadas, este proceso ocurre mayoritariamente en las etapas locales, pero no en sus etapas superiores. El artículo sugiere finalmente, que cambios en las reglas de selección de las conferencias analizadas pueden contribuir a cambiar este escenario.

Palabras clave: conferencias de políticas públicas; inclusión política; reclutamiento; selección y reglas institucionales 


\section{Résumé}

Inclusion politique? Recrutement et sélection des acteurs dans les conferences de politique publique

L'article évalue de façon comparative la capacité inclusive des Conférences sur la Santé et les Services Sociaux qui se sont réalisées en 2011, dans le Minas Gerais, à travers une stratégie analytique qui comprend trois étapes distinctes. Grâce à l'enquête menée auprès de 729 participants à ces conférences, nous analyserons (1) qui sont les participants de ces conférences, (2) la mise à l'échelle de l'impact sur le profil socio-économique et politique de ces participants et (3) les règles relatives au recrutement (qui peut participer) et à l'élection des représentants-délégués dans ces innovations. L'article démontre que, bien que les Conférences de politiques publiques visent à inclure de nouvelles voix à l'échelle nationale au processus de discussion et de décision des politiques publiques auxquelles elles sont liées, ce processus se déroule principalement sur les étapes locales, mais pas dans les étapes supérieures. L'article suggère aussi que des changements dans les règles de sélection des conférences analysées peuvent contribuer à changer ce contexte.

Mots-clés: conférences de politiques publiques; inclusion politique; recrutement; sélection et règles institutionnelles

Artigo submetido à publicação em 26 de março de 2017. Versão final aprovada em 27 de outubro de 2017. 